D) Check for updates

Cite this as: $B M J 2021 ; 374: n 1936$ http://dx.doi.org/10.1136/bmj.n1936 Published: 02 August 2021

\section{Glucocorticoid induced adrenal insufficiency}

The heading of the third column in table 2 of this state of the art review (BMJ 2021;374:n1380, 12 July 2021, doi:) by Prete and Bancos has been corrected to give the prednisolone reference dose as $5 \mathrm{mg}$ (rather than 5 g). 